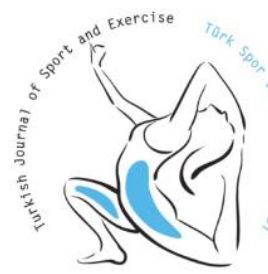

ISSN: 2147-5652

\title{
Mental skill usage of athletes with physical disabilities*
}

\author{
Ferhat ESATBEYOGLU1, Mark CAMPBELL²
}

\author{
${ }^{1}$ Hacettepe University, Division of Sport Sciences and Technology, Ankara,Turkey. \\ ${ }^{2}$ University of Limerick Department of Physical Education and Sport Sciences, Ireland. \\ *This work was submitted as a poster presentation during 14 ${ }^{\text {th }}$ European Congress of Sport Psychology on 14-19 July 2015, Bern, Switzerland proceeding \\ book, 75 . \\ Address correspondence to F.Esatbeyoglu, e-mail: ferhat.esatbeyoglu@hacettepe.edu.tr
}

\begin{abstract}
Mental skills training strategies should be beneficial for a variety of different skills, age groups and special populations. The purpose of the present research were twofold; initially to examine performance strategies in various sport situations used by volleyball, sitting volleyball and amputee soccer players, and comparing it among the sports; and secondly, whether the current performance level of athletes and the years participating in sport would show a significant difference in their application of psychological skills during practice and competition. The refined version of Test of Performance Strategies (TOPS) was administrated to athletes $(\mathrm{N}=309)$ competing across a range of performance standards in volleyball, sitting volleyball and amputee soccer sports. Results revealed that, relative to competition strategies, participants scored highest on activation and lowest on relaxation $(4.10 \pm 0.52 ; 3.03 \pm 0=1.04$, respectively) and in practice environment they scored highest on self-talk and lowest on relaxation $(3.84 \pm 0=.91 ; 2.80 \pm 0.98$, respectively). Examination of the results showed moderately strong correlations among many of the strategies in both competition and practice environments $(\mathrm{P}<0.01)$. Additionally, comparison of mental skills and strategies usage according to sports, discovered significant sport specific variations both in competition and practice settings $(\mathrm{P}<0.01)$. Investigation of current performance level differences in psychological skills and strategies explored differences among international, national and club level athletes $(\mathrm{P}<0.01)$. Exploration of years participating in sport comparison has also discovered differences among groups $(\mathrm{P}<0.01)$. These findings provide a unique insight into the mental skill usage of athletes with physical disabilities and their application to practise and environment settings.
\end{abstract}

Keywords: ParaVolley, amputee soccer, disability sport, psychological strategies, performance

\section{INTRODUCTION}

Determinants of success are multi-factorial and a combination of anthropometric, physical and psychological factors influences the sporting success that an athlete achieves. However, while physical characteristics have been found to discriminate between athletes in different sporting events, only psychological factors are able to explain the performances of athletes who are looking to maintain their success. Psychological skills are lauded for performance enhancement reasons, often their influence is direct (e.g., making a sound decision during a game), they are also important for their value beyond performance (e.g., team cohesion) and for their value in influencing performance in indirect ways (e.g., effective training) (23).
It is emphasized that psychological skills specifically, mental skills training strategies, should not only be applicable to elite athletes but also be beneficial for a variety of different skills, age groups and special populations $(33,34)$. Generally, the psychological skills training programmes for athletes with physical disabilities are not notably different to those for able-bodied athletes (12). Understanding the structure, use and potential benefits of mental skills training as applied to athletes with disabilities will allow these athletes to enhance their sporting performance and enjoyment of sport (11) and furthermore when given access to mental skills training programs, these athletes are usually very receptive and appreciative (10). The knowledge of the psychosocial attributes of Paralympic athletes could provide the sport psychologist with comprehensive 
and specific information on the athlete and his/her demands of performance (2).

There are existing studies carried out with athletes with disabilities in specific psychological domains. A study of 15 male athletes participating in the Amputee Soccer World Cup revealed that goal setting was the most used skill in competition, followed by activation, imagery, relaxation, self-talk, automaticity and emotional control. In practice, goal setting was also favoured, followed by automaticity, attention control, self-talk, emotional control, imagery, activation and lastly relaxation (21). In another study, Banack et al. investigated the motivation of Canadian Paralympic athletes (1). Their results suggested Paralympic athletes' perceptions of control predicted their feelings of independence and their connection to the coach and other athletes. Also, athletes' perceptions of ability and control predicted their inherent enjoyment of the sport. In a study of elite level wheelchair rugby players, it was found that comprehensive mental skills predicted an athlete's sport engagement (22). They reported that athletes who had strong mental skills such as the ability to concentrate and cope with adversity were more likely to report being dedicated and enthused about their disability sport involvement compared with athletes with weaker mental skills. Gregg et al. conducted research with Special Olympics track and field athletes (9). They replicated and extended the mental skills training (MST) package of Wanlin et al. (32) to three athletes with intellectual disabilities age ranged from 21 to 23 years. A multiple baseline design across individuals was used to assess the effects of the intervention on off-task behaviours and athletic performance (i.e., work output and competition results). The results were clearly beneficial for two participants, decreasing the frequency and duration of off-task behaviours and increasing the percentage of laps completed for the third participant. In addition, a model by Larsen, a six-step psychological-skills training (PST) program was developed for elite female athletes with visually impaired in Denmark (19). The aims of the program were to create a series of mental skills training sessions to train psychological skills and to prepare the players for the European Championships and qualification for the Paralympics. The six-step MST program was conducted during 6 of 8 training camps in 2011. The program was a success and the women's national team won the gold medal Turk ل Sport Exe 2018; 20(I): 27-37

( 2018 Faculty of Sport Sciences, Selcuk University and qualified for the 2012 Paralympics in London. Stamou et al. examined the effectiveness and preference of the two different types of self-talk (instructional and motivational) on penalty execution skill in goalball and gain insight on the athletes' perceptions concerning self-talk use and its influence on their performance (29). The sample consisted of six female athletes, all members of the national goalball team representing Greece in the Paralympic Games in Athens 2004. The results revealed a percentage difference on performance ranging from 1.5 per cent to 26.1 per cent for each athlete in favour of instructional self-talk. Finally, participants showed preference toward the use of instructional self-talk to improve their penalty execution skill. Also Eddy and Mellalie investigated qualitatively imagery experiences of six elite goalball players the processing and use of mental images in training and competition (8). Participants reported using imagery for cognitive and motivational purposes in both training and competition. Imagery was also suggested to be utilized from an internal perspective with the processing of images derived from a range of modalities. The authors highlighted that visual impairment does not restrict the ability to use mental imagery and that psychological interventions can be expanded to include the use of all the athletes' sensory modalities.

Hanrahan et al. stressed the significance of the reliability of psychological skills training measurements for athletes with disabilities and how mental training programs can be developed and implemented with this group of sport performers (10). With this regard they developed and implemented a 5 week psychological skills training program for visually impaired athletes. The program was designed to introduce participants to selected skills in a variety of areas in sport psychology (e.g., general awareness of the mental aspects of sport, body awareness, training and competition as learning experiences, relaxation, motivation, mental imagery). According to their findings all athletes reported that relaxation was a very beneficial skill and some athletes found that body awareness exercise helped them to get to know their body and this was not only useful for relaxation but also for sport performance. One of the other aspects that that received particular positive mention was goal setting. In conclusion, researchers came with a conclusion that the strategy used for this program, 
which was based on information compiled from ablebodied and sighted athletes, was successful with this group of blind athletes and only few changes were needed to accommodate for their disability.

Within our knowledge, study measuring mental skills with athletes with physical disabilities is limited. Additionally, most research on psychological skills has been focused on the able-bodied athletic population. On top of this, there is a dearth of knowledge in the disability sport context of how athletes with disabilities become more aware of their sport skills and knowledge from a sport psychology perspective. Therefore, the purposes of the present research were initially to examine performance strategies in various sport situations used by volleyball, sitting volleyball and amputee soccer players and comparing it among the sports; secondly, whether the current performance level of athletes and the years participating in sport would show a significant difference in their application of psychological skills during practice and competition; and thirdly, reflect and raise awareness of athletes with disabilities' sport skills and knowledge.

\section{MATERIALS \& METHODS}

Participants

A total of 309 participants (age $=32.46 \pm 12.40 \mathrm{yr}$ ) took part in this study. The sample consisted of in this study were 96 volleyball (31.06\%), 121 sitting volleyball (39.15\%) and 92 amputee soccer $(29.77 \%)$ players. Of those athletes who indicated their sex, 160 $(51.77 \%)$ were male and 149 female $(48.22 \%)$. A breakdown of the sample according to sport, gender, years participating in sport and current performance level is reported in Table 1. Research ethics approval was granted by the University of Limerick Research Ethics Committee (EHSREC11-31).

Table1.Breakdown of sample according to sport, gender, years participating in sport and current performance level.

\begin{tabular}{ccccccccc}
\hline & \multicolumn{2}{c}{ Gender } & \multicolumn{3}{c}{ Years } & \multicolumn{3}{c}{ Current Performance Level } \\
\hline Sport & Male & Female & $1-5$ & $6-10$ & $>10$ & International & National & Club \\
\hline $\begin{array}{c}\text { Volleyball } \\
n=96\end{array}$ & 31 & 69 & 51 & 31 & 18 & 46 & 34 & 16 \\
\hline $\begin{array}{c}\text { S.V } \\
n=121\end{array}$ & 27 & 79 & 28 & 49 & 23 & 60 & 319 & 45 \\
\hline $\begin{array}{c}\text { A.S. } \\
n=92\end{array}$ & 91 & 1 & 30 & 70 & 9 & 39 & 19 & 48 \\
\hline $\begin{array}{c}\text { Total } \\
n=309\end{array}$ & 160 & 149 & 109 & 150 & 50 & 145 & 47 \\
\hline
\end{tabular}

Table note: $\mathrm{S} . \mathrm{V}=$ Sitting volleyball, $\mathrm{A} . \mathrm{S}=\mathrm{Amputee}$ soccer

\section{Protocol}

Participants were provided with a covering letter and a detailed plan explaining the purposes and procedures of the study. The potential benefits to participants were that they could reflect and become more aware of their sport skills and knowledge. Collected data from participants were made anonymous. Of the 370 candidates, 21 opted out and 40 responded partial leaving an available participant pool of 309. If the survey was not responded within 15 days, then an email reminder was sent. If the original survey was not responded within 30 days after the email reminder was sent, a second online survey was sent to athletes. A hundred and twenty of the 309 athletes completed online survey which yielded useful data, providing a return rate of $83.51 \%$.

Turk J Sport Exe 2018; 20(I): 27-37

(c) 2018 Faculty of Sport Sciences, Selcuk University

\section{Instrument}

A refined version of the Test of Performance Strategies (TOPS) (13) was used to measure psychological skill and technique use. The TOPS was developed to overcome problems with the original TOPS scale. Specifically, in previous work with the original questionnaire, items from the subscales of attentional and emotional control in practice crossloaded onto a single factor (31). Furthermore, Lane et al. (18) found problems with activation and automaticity in practice and activation, emotional control, and negative thinking in competition. The new version of TOPS aimed to address these issues, but limitations remained (31). For example, a new competition subscale of distractibility had unacceptable low internal reliability $(\alpha=.44)$. Thus, 
the TOPS was further refined by the test developers to create the new version of TOPS. The TOPS omits a distractibility subscale, and introduces an attentional control subscale in competition. Further improvements to previous TOPS items were also made. Specifically, for emotional control in practice the negatively worded "I have trouble controlling emotions when things are not going well at practice" was changed to read "I can control my emotions when things are not going well at practice". It is this most updated version of the TOPS questionnaire which was adopted in the current study. Frequency of mental skill and technique use on the TOPS is calculated for 17 different subscales, eight for practice and nine for competition, and include goal setting, imagery, relaxation, self-talk, automaticity, activation, emotional control, and attentional control as well as negative thinking for competition only. Athletes respond to 68 items on a 5 -point Likert scale $(1=$ never to $5=$ always $)$, and mean subscale scores are calculated.

Thomas et al. (31) reported the Cronbach alpha coefficient for the TOPS .66 (automaticity, practice) to 0.81 (self-talk, practice) and Hardy et al. (13) reported Cronbach alpha coefficients for the TOPS ranging for practice settings from .71 (Activation) to .85 (Relaxation) and for competition settings from .62 (Automaticity) to .89 (Emotional control) in subsequent analyses. Cronbach's alpha was calculated to ascertain the internal reliability for each subscale for this study. Values above .70 are considered acceptable; however, values above .80 are preferable (28), although Loewenthal (20) has suggested that an alpha of .60 is acceptable for subscales containing only four items (for this study the practice-activation subscale, Cronbach's alpha=.59, was kept because of its extremely close proximity to acceptable standards). Cronbach alpha reliability analyses were conducted on the present data to evaluate the internal reliability of the items within each subscale (7). Alpha coefficients of the usable TOPS subscales ranged from .59 to .85 , four of which were deemed unacceptable. Cronbach's alpha reliability analysis identified low alpha for attentional control $(\alpha=.55)$ subscale in competition; and three subscales in practice; automaticity $(\alpha=.38)$, activation $(\alpha=-.116)$ and attentional control $(\alpha=.34)$. An item analysis review, conducted to determine if specific items from the four unacceptable subscales could be included or excluded in order to improve the reliability scores, failed to Turk ل Spart Exe 2018; 20(I): 27-37 increase the consistency, and so these subscales were not considered in the subsequent analysis. So those scales were not included to any further analyses but reliability only. The reliability coefficients for the subscales included in this study are displayed in Table 2.

\section{Statistical Analysis}

Analyses included descriptive statistics, Pearson product-moment correlations and multivariate analysis of variance (MANOVA). All data were checked for normality using the Kolmogorov-Smirnov test. Before differentiating between the various groups, descriptive statistics were computed to characterize the entire sample on each of the practice and competition performance strategies and psychological skills. Also, to further describe the subscales and elucidate the relationships between them, Pearson correlations were conducted between each of the competition and practice subscales, respectively. SPSS Statistics 22 was used for all analyses. Statistical significance was set $\mathrm{p}<0.05$.

\section{RESULTS}

Means and standard deviations of the total sample are shown in Table 2. Inspections of the results reveals that, relative to competition strategies, participants scored highest on activation (4.10 \pm 0.52$)$, automaticity $(3.97 \pm 1.02)$, and goal setting $(3.93 \pm 0.99)$ and lowest on relaxation $(3.03 \pm 1.04)$ and emotional control (3.21 \pm 1.09$)$. Moreover, with regards to practice strategies and skills, participants scored highest on self-talk $(3.84 \pm 0.91)$ and lowest on relaxation

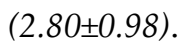

Correlations among each of the competition and practice subscales are displayed in Table 3 . Examination of the results shows moderately strong correlations among many of the strategies. Thus, for instance, the skilful use of self-talk in competition was positively associated with goal setting $(0.80, P<.01)$, imagery $(0.77, P<.01)$ and relaxation $(0.46, P<.01)$. Furthermore, strategic self-talk was inversely related to emotional control $(-.51, \quad P<.01)$. Self-talk was unrelated to negative thinking during competition, as indeed were most of other strategies. A similar pattern of relationships is evident for those strategies during practice. Self-talk correlated positively with goal setting $(0.72, P<.01)$, imagery $(0.72, P<.01)$ and relaxation $(0.60, P<.01)$. The skilful use of self-talk 
techniques in competition correlated strongly with the use of these techniques in practice $(0.82, P<.01)$. Significant correlations between the competition and practice contexts were also noted for imagery $(0.80$, $P<.01)$, emotional control $(0.74, P<.01)$, goal setting $(0.73, P<.01)$, and relaxation $(0.66, P<.01)$. In summary, athletes who use particular strategies in competition, such as self-talk, goal setting, imagery, emotional control, and activation, also tend to make use of the other strategies measured. The same applies during practice. Consequently, there is a considerable overlap in the use of particular mental strategies across the two performance contexts.

To examine differences in psychological skills and strategies, volleyball players, sitting volleyball players and amputee soccer players were compared in two different discriminant analyses, one for competition subscales and one for practice subscales. Table 4 contains the means, standard errors, F and significance level for each of the competition and practice subscales.

Table 2. Means, standard errors, and alpha coefficients for the TOPS.

\begin{tabular}{llll}
\hline Competition subscales & Mean & SE & $\alpha$ \\
\hline Self-talk & 3.70 & .99 & .85 \\
\hline Emotional control & 3.21 & 1.09 & .85 \\
\hline Automaticity & 3.97 & 1.02 & .60 \\
\hline Goal setting & 3.93 & .99 & .85 \\
\hline Imagery & 3.66 & .83 & .68 \\
\hline Activation & 4.10 & .52 & .59 \\
\hline Negative thinking & 3.66 & .93 & .73 \\
\hline Relaxation & 3.03 & 1.04 & .78 \\
\hline Practice subscales & Mean & SE & A \\
\hline Self-talk & 3.84 & .91 & .84 \\
\hline Emotional control & 3.06 & .62 & .68 \\
\hline Goal setting & 3.50 & .75 & .68 \\
\hline Imagery & 3.49 & .87 & .76 \\
\hline Relaxation & 2.80 & .98 & .73 \\
\hline Note: SE-Stand & & \\
\hline
\end{tabular}

Note: SE=Standard Error; $\alpha=$ Alpha coefficient.

Table 3. Correlations between scores on the competition and practice subscales.

\begin{tabular}{lccccccccc}
\hline & 1 & 2 & 3 & 4 & 5 & 6 & 7 & 8 & 9 \\
\hline 1.Self - talk & $\mathbf{1}$ & -.45 & - & $.72^{* *}$ & $.72^{* *}$ & - & $.60^{* *}$ & - & - \\
\hline 2.Emotional control & $-.51^{* *}$ & $\mathbf{1}$ & - & -.49 & -.46 & - & -.42 & - & - \\
\hline 3.Automaticity & .36 & -.16 & $\mathbf{1}$ & $.63^{* *}$ & $.73^{* *}$ & - & $.64^{* *}$ & - & - \\
\hline 4.Goal setting & $.80^{* *}$ & -.42 & .42 & $\mathbf{1}$ & $.58^{* *}$ & - & .48 & - & - \\
\hline 5.Imagery & $.77^{* *}$ & $-.58^{* *}$ & .44 & $.75^{* *}$ & $\mathbf{1}$ & - & $.69^{* *}$ & - & - \\
\hline 6.Activation & .34 & .08 & .46 & .47 & .34 & $\mathbf{1}$ & .30 & - \\
\hline 7.Relaxation & .46 & -.35 & .28 & .34 & $.50^{* *}$ & .06 & $\mathbf{1}$ & - \\
\hline 8.Negative thinking & -.21 & $.68^{* *}$ & .06 & -.20 & -.27 & .13 & -.11 & - \\
\hline 9.Attentional control & - & - & - & - & - & - & - & - \\
\hline
\end{tabular}

${ }^{* *}$ Correlation trends at $\mathrm{p}=0.01$. Correlations among competition subscales are in the lower left diagonal, and those for practice subscales are in the upper right diagonal.

Competition analysis. A significant multivariate effect of context was found (Wilks'^ $=0.510, F_{16}$, $\left.{ }_{198}=4.945, \mathrm{p}<.05\right)$. Inspection of the standardized discriminant function coefficients revealed that selftalk, emotional control, goal setting, imagery, relaxation and negative thinking contributed most to the discrimant function. Specifically, sitting volleyball players scored higher on self-talk $(4.09 \pm 0.56)$, goal setting $(4.34 \pm 0.56)$, imagery $(4.04 \pm 0.58)$ than volleyball
$(3.40 \pm 1.18 ; \quad 3.47 \pm 1.36 ; \quad 3.35 \pm 1.0, \quad$ respectively $)$ and amputee soccer players $(3.13 \pm 0.13 ; 3.53 \pm 0.86 ; 3.15 \pm 0.64$, respectively). Moreover, sitting volleyball players $(3.31 \pm 1.03)$ and amputee soccer players $(3.11 \pm 0.85)$ reported using more relaxation techniques than volleyball players (2.43土.99) in competition environment. Amputee soccer players (3.65 \pm 0.14 ; $3.98 \pm 0.70$, respectively) and volleyball players (3.92 \pm .81 ; $4.04 \pm 0.68$, respectively) scored higher on emotional 
control and negative thinking than sitting volleyball players $(2.66 \pm 0.98 ; 3.32 \pm 1.01$, respectively).

Table 4. Comparison of competition and practice scores on the TOPS among volleyball, sitting volleyball and amputee soccer players.

\begin{tabular}{|c|c|c|c|c|c|c|c|c|}
\hline \multirow[b]{2}{*}{ Competition subscales } & \multicolumn{2}{|c|}{ Volleyball } & \multicolumn{2}{|c|}{ Sitting volleyball } & \multicolumn{2}{|c|}{ Amputee soccer } & \multirow[b]{2}{*}{$\mathbf{F}$} & \multirow[b]{2}{*}{ Sig. } \\
\hline & $\mathbf{M}$ & SE & $\mathbf{M}$ & SE & $\mathbf{M}$ & SE & & \\
\hline Self-talk & 3.40 & 1.18 & 4.09 & .56 & 3.13 & 1.13 & 11.46 & $.000^{* * *}$ \\
\hline Emotional control & 3.92 & .81 & 2.66 & .98 & 3.65 & .94 & 21.14 & $.000 * *$ \\
\hline Automaticity & 3.85 & .79 & 4.13 & 1.21 & 3.76 & .72 & 1.37 & .256 \\
\hline Goal setting & 3.47 & 1.36 & 4.34 & .56 & 3.53 & .86 & 11.80 & $.000 * *$ \\
\hline Imagery & 3.35 & 1.01 & 4.04 & .58 & 3.15 & .64 & 15.83 & .000 *** \\
\hline Activation & 4.07 & .65 & 4.18 & .45 & 3.93 & .61 & 1.78 & .173 \\
\hline Relaxation & 2.43 & .99 & 3.31 & 1.03 & 3.11 & .85 & 7.92 & $.001^{* * *}$ \\
\hline Negative thinking & 4.04 & .68 & 3.32 & 1.01 & 3.98 & .70 & 8.64 & $.000^{* * *}$ \\
\hline Practice subscales & $\mathbf{M}$ & SE & $\mathbf{M}$ & SE & $\mathbf{M}$ & SE & $\mathbf{F}$ & Sig. \\
\hline Self-talk & 3.52 & 1.16 & 4.16 & .55 & 3.47 & .98 & 7.99 & .001 *** \\
\hline Emotional control & 3.37 & .77 & 2.82 & .92 & 3.25 & .81 & 4.71 & $.011^{*}$ \\
\hline Goal setting & 3.12 & .77 & 3.84 & .62 & 3.18 & .67 & 14.20 & .000 ** * \\
\hline Imagery & 3.17 & .74 & 3.90 & .65 & 2.94 & 1.01 & 16.26 & .000 *** \\
\hline Relaxation & 2.38 & .88 & 3.14 & .96 & 2.50 & .87 & 8.14 & $.001^{* * * *}$ \\
\hline
\end{tabular}

Note: $p<0.05,{ }^{* *} p<0.01$

Practice analysis. A significant multivariate effect of context was found (Wilks' $\wedge=0.680, \mathrm{~F}_{10,204}=4.347$, $\mathrm{p}<.05)$. Findings revealed that sitting volleyball

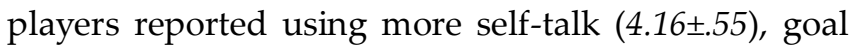
setting (3.84 \pm 0.62$)$, imagery $(3.90 \pm 0.65)$ and relaxation $(3.14 \pm 0.96)$ than amputee soccer players $(3.47 \pm 0.98$; $3.18 \pm 0.67 ; \quad 2.94 \pm 1.01 ; \quad 2.50 \pm 0.87$, respectively) and volleyball players $(3.52 \pm 1.16 ; 3.12 \pm 0.77 ; 3.17 \pm 0.74$; $2.38 \pm 0.88$, respectively). And also, emotional control scores of volleyball players $(3.37 \pm 0.77)$ and amputee soccer players $(3.25 \pm 0.81)$ were high than sitting volleyball players $(2.82 \pm 0.92)$.

\section{Comparison in current performance level}

In an exploratory investigation of current performance level differences in psychological skills and strategies, international, national and club $(n=21$, $19.26 \%$ ) level participants were compared in two different discriminant analyses, one for competition subscales and one for practice subscales. Results of a multivariate analysis of variance are shown in Table 5.

Competition analysis. A significant multivariate effect of context was found (Wilks'^ $=0.678, \mathrm{~F}_{16}$, $198=2.656, \mathrm{p}<.05)$. Inspection of the standardized discriminant function coefficients revealed that, selftalk, emotional control, goal setting, imagery, negative thinking, and relaxation contributed most to the discrimant function. Specifically, international and national players reported more usage of self-talk $(3.87 \pm 0.88 ; \quad 3.90 \pm 0.94$, respectively), goal setting $(4.18 \pm 0.82 ; 4.03 \pm 0.82$, respectively), and imagery $(3.88 \pm 0.73 ; 3.78 \pm 0.58$, respectively) than club level players (2.96 $\pm 1.04 ; 3.03 \pm 1.17 ; 2.85 \pm .87$, respectively). Additionally, international players scored higher on relaxation $(3.20 \pm 1.02)$ than club players $(2.39 \pm 1.05)$. Surprisingly, club level players scored higher on emotional control (3.95 \pm 0.98$)$ and negative thinking $(4.10 \pm 0.68)$ than international players $(2.95 \pm 1.10$; $3.45 \pm .97$, respectively).

Practice analysis. The results of the discriminant analysis on the 5 practice subscales was also significant $\left(\right.$ Wilks'^ $=0.567, \mathrm{~F}_{10}, 204=6.699, \mathrm{p}<.05$ ). Inspection of the standardized discriminant function coefficients revealed that, self-talk, emotional control, goal setting, imagery and relaxation made the most significant contributions to the separation between groups. Clearly, international players scored higher on self-talk $(4.06 \pm 0.71)$, goal setting $(3.67 \pm 0.70)$, imagery $(3.73 \pm 0.76)$ and relaxation $(3.02 \pm 1.00)$ than club level players $\quad(2.94 \pm 1.01 ; 3.17 \pm 0.88 ; 2.91 \pm 0.96 ; 2.19 \pm 0.97$, respectively). And furthermore, national level players scored higher on self-talk $(4.02 \pm 0.83)$ than club level players $(2.94 \pm 1.01)$. With respect to emotional control subscale, club level players (3.65 \pm 0.65$)$ scored higher than international $(2.94 \pm 0.97)$ and national level players $(2.83 \pm 0.46)$. 
Table 5. Comparison of competition and practice scores on the TOPS among international, national and club level.

\begin{tabular}{|c|c|c|c|c|c|c|c|c|}
\hline \multirow[b]{2}{*}{ Competition subscales } & \multicolumn{2}{|c|}{ International } & \multicolumn{2}{|c|}{ National } & \multicolumn{2}{|c|}{ Club } & \multirow[b]{2}{*}{$\mathbf{F}$} & \multirow[b]{2}{*}{ Sig. } \\
\hline & $\mathbf{M}$ & $\mathrm{SE}$ & $\mathbf{M}$ & $\mathrm{SE}$ & $\mathbf{M}$ & SE & & \\
\hline Self-talk & 3.87 & .88 & 3.90 & .94 & 2.96 & 1.04 & 8.22 & $.000 * *$ \\
\hline Emotional control & 2.95 & 1.10 & 3.33 & .78 & 3.95 & .98 & 7.67 & $.001^{* * *}$ \\
\hline Automaticity & 4.07 & 1.12 & 3.95 & .80 & 3.69 & .82 & 1.15 & .319 \\
\hline Goal setting & 4.18 & .82 & 4.03 & .82 & 3.03 & 1.17 & 13.13 & $.000^{* * *}$ \\
\hline Imagery & 3.88 & .73 & 3.78 & .58 & 2.85 & .87 & 15.75 & .000 ** \\
\hline Activation & 4.16 & .48 & 4.07 & .73 & 3.92 & .54 & 1.51 & .224 \\
\hline Relaxation & 3.20 & 1.02 & 3.11 & .92 & 2.39 & 1.05 & 5.27 & $.007^{*}$ \\
\hline Negative thinking & 3.45 & .97 & 3.88 & .79 & 4.10 & .68 & 4.93 & $.009^{*}$ \\
\hline Practice subscales & $\mathbf{M}$ & SE & $\mathbf{M}$ & SE & $\mathbf{M}$ & SE & $F$ & Sig. \\
\hline Self-talk & 4.06 & .71 & 4.02 & .83 & 2.94 & 1.01 & 16.38 & .000 ** * \\
\hline Emotional control & 2.94 & .97 & 2.83 & .46 & 3.65 & .65 & 6.42 & $.002 * *$ \\
\hline Goal setting & 3.67 & .70 & 3.27 & .64 & 3.17 & .88 & 4.94 & $.009^{*}$ \\
\hline Imagery & 3.73 & .76 & 3.30 & .79 & 2.91 & .96 & 8.92 & .000 ** \\
\hline Relaxation & 3.02 & 1.00 & 2.67 & .59 & 2.19 & .97 & 6.54 & $.002 * *$ \\
\hline
\end{tabular}

Note:* $p<0.05, * * p<0.01$

Table 6. Comparison of competition and practice scores on the TOPS among years participating in sport.

\begin{tabular}{|c|c|c|c|c|c|c|c|c|}
\hline \multirow[b]{2}{*}{ Competition Subscales } & \multicolumn{2}{|c|}{$\begin{array}{l}\text { Group 1: } \\
1-5 \text { years }\end{array}$} & \multicolumn{2}{|c|}{$\begin{array}{l}\text { Group 2: } \\
\text { 6-10 years }\end{array}$} & \multicolumn{2}{|c|}{$\begin{array}{l}\text { Group 3: } \\
>10 \text { years }\end{array}$} & \multirow[b]{2}{*}{ F } & \multirow[b]{2}{*}{ Sig. } \\
\hline & $\mathbf{M}$ & SE & $\mathbf{M}$ & SE & $\mathbf{M}$ & $\mathrm{SE}$ & & \\
\hline Self-talk & 3.50 & .95 & 3.71 & 1.17 & 4.09 & .63 & 2.94 & .057 \\
\hline Emotional control & 3.07 & 1.09 & 3.62 & 1.02 & 2.94 & 1.05 & 3.72 & .027 \\
\hline Automaticity & 3.65 & .68 & 4.33 & 1.52 & 4.16 & .39 & 5.32 & $.006^{*}$ \\
\hline Goal setting & 3.75 & 1.02 & 3.94 & 1.11 & 4.32 & .64 & 2.77 & .067 \\
\hline Imagery & 3.55 & .81 & 3.66 & .97 & 3.90 & .61 & 1.42 & .244 \\
\hline Activation & 3.96 & .57 & 4.22 & .55 & 4.23 & .42 & 3.32 & .040 \\
\hline Relaxation & 2.98 & 1.06 & 2.94 & 1.16 & 3.27 & .81 & .80 & .449 \\
\hline Negative thinking & 3.64 & .91 & 4.02 & .80 & 3.19 & .95 & 6.05 & $.003^{* * *}$ \\
\hline Practice Subscales & $\mathbf{M}$ & SE & $\mathbf{M}$ & SE & $\mathbf{M}$ & SE & $\mathbf{F}$ & Sig. \\
\hline Self-talk & 3.77 & .92 & 3.72 & 1.03 & 4.15 & .61 & 1.90 & .154 \\
\hline Emotional control & 3.02 & .92 & 3.33 & .65 & 2.75 & 1.02 & 3.27 & $.042^{*}$ \\
\hline Goal setting & 3.34 & .78 & 3.36 & .66 & 4.05 & .57 & 9.16 & $.000 * * *$ \\
\hline Imagery & 3.45 & .88 & 3.45 & .94 & 3.64 & .73 & .43 & .650 \\
\hline Relaxation & 2.72 & .94 & 2.63 & .98 & 3.19 & 1.01 & 2.66 & .074 \\
\hline
\end{tabular}

Note:* $p<0.05,{ }^{* *} p<0.01$

\section{Years participating in sport comparison}

To explore years participating in sport in psychological skills and strategies, participants were separated into three groups. Group 1 consisted of athletes whose years participating in sport range from 1-5 years, Group 2 consisted of athletes whose years participating in sport range from 6-10 years, and Group 3 consisted of the athletes participating in sport more than 10 years. Comparisons were made in two different discriminant analyses, one for competition subscales and one for practice subscales. Results of a multivariate analysis of variance are presented in Table 6.
Competition analysis. A significant multivariate effect of context was found (Wilks'^ $=0.697, F_{16}$, $\left.{ }_{198}=2.450, \mathrm{p}=.05\right)$. The results showed that automaticity and negative thinking contributed most to the discrimant function. Specifically, Group 2 scored higher on automaticity $(4.33 \pm 1.52)$ skill usage than Group 1 (3.65 \pm 0.68$)$. Additionally, Group 2 also reported less negative thinking $(4.02 \pm 0.80)$ during competition environment than Group $3(3.19 \pm 0.95)$.

Practice analysis. The result of the discriminant analysis of the five practice subscales was significant (Wilks'^ = 0.766, F10, 204=2.913, p=.05). Briefly, Group 2 scored higher on emotional control $(3.33 \pm 0.65)$ than Group 3 (2.75 \pm 1.02$)$. And furthermore, Group 3 
reported more goal setting usage $(4.05 \pm 0.57)$ in practice than Group $1(3.34 \pm 0.78)$ and Group 2 (3.36 \pm 0.66$)$.

\section{DISCUSSION}

The main objective of the research study was to examine psychological skills usage of athletes in various sport situations used by sitting volleyball players and comparing it with standing volleyball players and amputee soccer players. The results of the current study revealed that sitting volleyball players impressively, scored higher on self-talk, goal setting, imagery and relaxation than volleyball players both in competition and practice settings. And similarly, amputee soccer players scored higher on relaxation than volleyball players in competition environment. These findings are worth to mention and discuss. Perhaps sitting volleyball players and amputee soccer players cannot train as long as volleyball players and so they may have to recruit greater psychological skills such as imagery or relaxation to help them train, practice and compete. Secondly, sitting volleyball and amputee soccer players have been forced, because of their injuries, to develop their mental skills more fully than volleyball players. In a sport setting, mental skills are targeted in a very specific way by coaches, athletes and sport psychologists, and as such athletes in general may be more likely to have a heightened awareness of the use of such skills and their purposes. Of some interest is the finding that use of mental skills did significantly differ as a function of exposure to sport psychology, indicating that some athletes are either being exposed to mental skills through alternative sources such as coaches, other athletes and reading material, or that such skills spontaneously occur without direct assistance.

Participation in athletic events can be a key source of stress for many athletes $(17,25)$. Thus, it is not surprising that sitting volleyball players and amputee soccer players reported using relaxation skills both in competition and practice settings. Relaxation is necessary for optimal performance. Further, athletes well practiced in using relaxation strategies can immediately experience physical results such as a decrease in heart rate and muscle tension (35). These results are tangible and therefore the benefits of using relaxation and stress control strategies are more evident. With respect to goal setting, a significant difference was found in the sitting volleyball players' Turk ل Sport Exe 2018; 20(I): 27-37 use of this skill in practice and competition than volleyball and amputee soccer players. An examination of the practice structure may partially explain this result. Sitting volleyball players could be provided an activity schedule before each practice by the coaching staff. This schedule could comprise a detailed description of the drills to be worked on at that practice along with the approximate time to be spent in each. This information allows the athletes to have an active role in setting targets for performance and lends itself well to the use of goal setting (3). The use of goal setting in competition was also statistically significant. Perhaps this was because competitions were perceived by the sitting volleyball players as a high structured environment involving more anticipated events and familiarity of opponents. Supporting this finding, a study showed that multifaceted goal setters, those athletes who set specific, short-term goals, psychological goals and competitive goals had more confidence, and greater career sport success than athletes who were disillusioned with the goal setting process or who were nonbelievers in the effectiveness of setting goals (4).

Results showed significant usage of imagery and self-talk for sitting volleyball players both in competition and practice. This finding is very consistent with literature in terms of competition $(5,15)$ and practice environment $(6,16)$. Stamou et al. examined the effectiveness and preference of the two different types of self-talk (instructional and motivational) on penalty execution skill in goalball and gain insight on the athletes' perceptions concerning self-talk use and its influence on their performance (29). The sample consisted of six female athletes, all members of the national goalball team representing Greece in the Paralympic Games in Athens 2004. The results revealed a percentage difference on performance ranging from 1.5 per cent to 26.1 per cent for each athlete in favour of instructional self-talk. Finally, participants showed preference toward the use of instructional self-talk to improve their penalty execution skill. And also imagery scores of sitting volleyball players were higher than amputee soccer players. With regards to imagery usage, there is also supporting evidence. Eddy and Mellalieu investigated qualitatively imagery experiences of six elite goalball players the processing and use of mental images in training and competition 
(8). Participants reported using imagery for cognitive and motivational purposes in both training and competition. Imagery was also suggested to be utilized from an internal perspective with the processing of images derived from a range of modalities. The authors highlighted that visual impairment does not restrict the ability to use mental imagery and that psychological interventions can be expanded to include the use of all the athletes' sensory modalities. These skills may have been very effective in competition and in practice for these athletes because of their perceptions regarding their beneficial use. These athletes might consider failing in practice is as significant as failing in a game. Therefore, sitting volleyball players are apt to use their imagery and self-talk to mentally prepare and employ both during competition. The findings of this study in terms of psychological skills usage of sitting volleyball players compared with volleyball and amputee soccer players, suggest that sitting volleyball players were applying these skills in practice and competition.

Volleyball players reported more emotional control and less negative thinking in competition settings than sitting volleyball players and more emotional control in practice settings. There is evidence in sport literature that a range of positive and negative emotions play a role in performance variability, by facilitating or impairing performance of athletes ${ }^{31}$. With regards to negative thinking, though in theory stopping negative thoughts might sound simple; in reality it is not so easy. Therefore learning techniques such as thought-stopping and countering can assist sitting volleyball players in dealing effectively with negative self-talk.

The analyses successfully distinguished between international, national and club level players in competition and practice. This finding suggest that international and national players more frequently employ psychological skills and strategies, in both practice and competitive environments, than club level players. Using the TOPS, Thomas et al., for example, successfully discriminated between international athletes and college, regional, and recreational performers (31). These researchers found significant differences for self-talk, emotional control, goal setting, imagery, activation, negative thinking and relaxation. Harwoord et al. reported that young elite athletes reported using significantly more imagery, goal setting, and positive self-talk skills when compared with their counterparts (14) and Neil et al. found that elite rugby union players to have significantly greater usage of relaxation, imagery, and self-talk compared to non-elite players (26).

Relative to competition strategies, international and national players scored highest on self-talk, goal setting, and imagery than club level players and international players scored higher on relaxation than club players. No difference was found in automaticity and activation scores among international, national and club level. These automaticity and activation scores, however, were still higher than that found by Thomas et al. and Hardy et al. in a more heterogeneous sample, ranging from internationallevel competitors to recreational players $(31,16)$; Taylor at al. in more diverse sports (30). One potential explanation of no significant difference is that the sample included athletes from 3 different sports, and it is likely that athletes judge automaticity relative to the demands of their own sport. That is, automaticity for a sitting volleyball player is probably much different than for a soccer player, but both may experience it in their own way and to an equal extent. Given this, it is possible that sport psychology researchers need to better study automaticity across sport contexts.

The current study generated several important findings regarding the psychological skills usage of volleyball, sitting volleyball and amputee soccer players; however, certain limitations must be discussed and should be taken into consideration for future research. First, the return rate was low $(46.98 \%)$. Further research and a larger sample size are needed to be able to generalize the findings of this study. Second, we recognize that more sophisticated statistical analyses (e.g., confirmatory factor analyses) with larger sample size are needed to establish the factor structure of the TOPS with greater confidence. Additionally, our study demonstrated that 4 out of 17 subscales possessed inadequate internal consistency for attentional control subscale in competition and attentional control, activation and automaticity subscales in practice settings. Activation and automaticity subscales in practice were reported also problematic in previous researches $(18,30)$. Moreover, despite its widespread use in sport psychology research, we acknowledge the limitations inherent in 
self-report measures (27) and recognize that research on psychological skills may be enhanced by the use of alternative methods of studying psychological strategies, such as concurrent cognitive process tracing measures.

In conclusion future research needed, using psychological skills instruments after assessing psychological skills training interventions, mental skills training packages, case studies of psychological skills training and investigating qualitatively psychological skills can give coaches, practitioners and sport psychologists better idea to capture and evaluate which skills contribute most and work, develop on low psychological skills profiles of athletes.

\section{Acknowledgements}

The authors thank to World ParaVolley Sport Organization and Irish Amputee Football Association for their support.

\section{Conflict of Interest}

The authors certify that there is no conflict of interest with any financial organization regarding the material discussed in the manuscript.

\section{REFERENCES}

1. Banack HR, Sabiston CM, Bloom GA. Coach autonomy support, basic need satisfaction, and intrinsic motivation of Paralympic athletes. Research Quarterly for Exercise and Sport, 2011; 82(4): 722-730.

2. Blumenstein B, Orbach I. Psychological preparation for Paralympic athletes: A preliminary study. Adapted Physical Activity Quarterly, 2015; 32(3): 241-255.

3. Burton D, Naylor S, Holliday B. Goal-setting in sport: Investigating the goal effectiveness paradox. In: Handbook of research on sport psychology, Singer R, Hausenblas HA and Janelle CM, eds. New York: Wiley, 2001.

4. Burton D, Pickering M, Weinberg R, Yukelson D, Weigand D. The competitive goal effectiveness paradox revisited: Examining the goal practices of prospective Olympic athletes. Journal of Applied Sport Psychology, 2010; 22(1): 72-86.

5. Calmels C, Berthoumieux C, d'Arripe LF. Effects of an imagery training program on selective attention of national softball players. Sport Psychology, 2004; 18(3): 272-296.

6. Calmels C, Holmes P, Berthoumieux C, Singer RN. The development of movement imagery vividness through a structured intervention in softball. Journal of Sport Behavior, 2004; 27(4): 307-322.

Turk ل Sport Exe 2018; 20(I): 27-37

田 2018 Faculty of Sport Sciences, Selcuk University
7. Cronbach LJ. Test validation. In: Educational measurement, RL Thorndike, ed. Washington, DC: American Council on Education, 1971.

8. Eddy KAT, Mellalieu SD. Mental imagery in athletes with visual impairments. Adapted Physical Activity Quarterly, 2003; 20(4): 347-368.

9. Gregg MJ, Hrycaiko D, Mactavish JB, Martin GL. A mental skills package for special Olympic athletes: A preliminary study. Adapted Physical Activity Quarterly, 2004; 21(1): 4-18.

10. Hanrahan SJ, Grove JG, Lockwood RJ. Psychological skills training for the blind athlete: a pilot program. Adapted Physical Activity Quarterly, 1990; 7(2): 143-155.

11. Hanrahan SJ. Sport psychology and athletes with disabilities. In: Sport Psychology: theory, applications and issues, Morris $\mathrm{T}$ and Summers J, eds. John Wiley and Sons Australia Ltd, 2004.

12. Hanrahan SJ. Psychological skills training for athletes with disabilities. Australian Psychologist, 2015; 50(2): 102-105.

13. Hardy L, Roberst R, Thomas PR, Murphy SM. Test of Performance Strategies (TOPS): Instrument refinement using confirmatory factor analysis. Psychology of Sport and Exercise, 2010; 11(1): 27-35.

14. Harwood C, Cumming J, Fletcher D. Motivational profiles and psychological skills use within elite youth sport. Journal of Applied Sport Psychology, 2004; 16(4): 318-332.

15. Horn CM, Gilbert JN, Gilbert W, Lewis DK. Psychological skills training with community college athletes: The UNIFORM approach. Sport Psychologist, 2011; 25(3): 321-340.

16. Johnson JJM, Hrycaiko DW, Johnson GV, Halas JM. Self-talk and female youth soccer performance. Sport Psychologist, 2004; 18(1): 44-59.

17. Jordet G. When superstars flop: Public status and choking under pressure in international soccer penalty shootouts. Journal of Applied Sport Psychology,2009; 21(2): 125-130.

18. Lane MA, Harwood C, Terry PC, Karageorghis. Confirmatory factor analysis of the Test of Performance Strategies (TOPS) among adolescent athletes. Journal of Sports Science, 2004; 22(9): 803-812.

19. Larsen $\mathrm{CH}$. Preparing for the European Championships: A sixstep mental skills training program in disability sports. Journal of Sport Psychology in Action, 2014; 5(4): 186-197.

20. Loewenthal, KM. An introduction to psychological tests and scales. London: UCL Press, 2001.

21. Lowther J, Lane A and Lane H. Self-efficacy and psychological skills during the Amputee Soccer World Cup. Athletic Insight: The Online Journal of Sport Psychology, 2002; 4(2): 23-34.

22. Martin JJ, Malone L. Elite wheelchair rugby players' mental skills and sport engagement. Journal of Clinic Sports Psychology, 2013; 7(4): 253-263.

23. Martin JJ. Determinants of elite disability sport performance. Kinesiology Review, 2015; 4(1): 91-98.

24. Mellalieu SD, Hanton S, Fletcher D. A competitive anxiety review: recent directions in sport psychology research. In: 
Literature reviews in sport psychology, Hanton S and Mellalieu SD, eds. New York: Nova Science, 2006.

25. Mesagno C, Marchant D, Morris T. Alleviating choking: The sounds of distraction. Journal of Applied Sport Psychology, 2009; 21(2): 131-147.

26. Neil R, Mellalieu SD, Hanton S. Psychological skills usage and the competitive anxiety response as a function of skill level in rugby union. Journal of Sports Science and Medicine, 2006; 5(3): 415-423.

27. Nisbett RE, Wilson TD. Telling more than we can know: Verbal reports on mental processes. Psychology Review, 1997; 84(3): 231-259.

28. Pallant J. SPSS, Survival Manual. The McGraw-Hill Companies, 2007.

29. Stamou E, Theodorakis Y, Kokaridas D, Perkos S, Kessanopoulou M. The effect of self-talk on the penalty execution in goalball. British Journal of Visual Impairment, 2007; 25(3): 233-247.
30. Taylor MK, Gould D, Rolo C. Performance strategies of US Olympians in practice and competition. High Ability Studies, 2008; 19(1): 19-36.

31. Thomas PR, Murphy MS, Hardy L. Test of performance strategies: Development and preliminary validation of a comprehensive measure of athletes' psychological skills. Journal of Sports Science, 1999; 17(9): 697-711.

32. Wanlin CM, Hrycaiko DW, Martin GL, Mahon, M. The effects of a goal-setting package on the performance of speed skaters. Journal of Applied Sport Psychology, 1997; 9(2): 212228.

33. Weinberg RS, Williams JM. Integrating and implementing a psychological skills training program. In: Applied Sport Psychology, Williams JM, ed. New York, The McGraw-Hill Companies, 2010.

34. Weinberg RS, Gould D. Foundations of sport and exercise psychology. Champaign ,IL: Human Kinetics; 2011.

35. Williams JM. Relaxation and energizing techniques for regulation of arousal. Applied sport psychology: Personal growth for peak performance. New York, NY: McGraw Hill, 2010. 